\title{
Comparative Study of Hemorrhoidectomy and Rubber Band Ligation in Treatment of Second and Third Degree Hemorrhoids in Kashmir
}

\author{
Mushtaq A. Gagloo • S. Wardul Hijaz • S. Aijaz Nasir • \\ Arjmand Reyaz • I. H. Bakshi • Nisar A. Chowdary • \\ Sameer A. Naqash $\cdot$ Banday M. Sharief
}

Received: 9 February 2011 / Accepted: 5 April 2012 / Published online: 28 April 2012

(C) Association of Surgeons of India 2012

\begin{abstract}
The diagnosis of hemorrhoids is primarily based on the proctoscopic examination. The study evaluates comparative results of rubber band ligation (RBL) and hemorrhoidectomy. This study was conducted over a period of $1 \frac{1 / 2}{2}$ year from Jan 2003 to June 2004. It includes 100 patients having second- or third-degree primary hemorrhoids who attended surgical OPD of SMHS Hospital Srinagar, Kashmir. These 100 patients were selected randomly and divided into two groups of 50 patients each (hemorrhoidectomy group and RBL group). Each patient was subjected to sigmoidoscopy to exclude other lesion higher up in rectosigmoid. Patients of fissure, fistulae, and malignancy were excluded. All parameters were recorded and finally analysed. The statistical analysis of the study was done using SPSS statistical package in which we used descriptive statistics and correlation analysis for the final evaluation. Hemorrhoidectomy and RBL are equally effective especially in second-degree hemorrhoids. However, RBL should be considered the first-line treatment in second-degree hemorrhoids because being an outpatient procedure, it is cost effective for the patients, saves many a hospital beds for more sick patients, and takes the pressure off the surgical waiting list. Although RBL is not as effective as hemorrhoidectomy in third-degree hemorrhoid, it does improve bleeding and
\end{abstract}

M. A. Gagloo • S. W. Hijaz (凶) • A. Reyaz I. H. Bakshi •

N. A. Chowdary $\cdot$ S. A. Naqash

Department of Surgery, SKIMS, SOURA,

Srinagar, Kashmir, India

e-mail: drwardulh@yahoo.com

\section{S. A. Nasir}

Department of Medicine, SKIMS, SOURA,

Srinagar, Kashmir, India

B. M. Sharief

Department of Clinical Pharmacology, SKIMS, SOURA,

Srinagar, Kashmir, India prolapse and is highly recommended for patients who are unfit for surgery or have concurrent disease that contraindicates anesthesia. RBL should be considered as the first-line treatment for second-degree hemorrhoid. However, in the third-degree hemorrhoids, hemorrhoidectomy achieves better results, and $\mathrm{RBL}$ is recommend as the first-line treatment for those patients in whom there is contraindication for surgery or anesthesia.

Keywords Hemorrhoidectomy $\cdot$ Rubber band ligation $(\mathrm{RBL}) \cdot$ Proctoscopy $\cdot$ Sigmoidoscopy

\section{Introduction}

The anal canal is lined in upper two-thirds by columnar epithelium and in the lower third by the squamous epithelium, which meets at the dentate line. In the upper anal canal, there are subepithelial vascular cushions continuous with the rectal columns above, which when distended give stellate (triradiate) cross section to anal lumen. These cushions are suspended in the anal canal by a connective tissue framework derived from internal anal sphincter and longitudinal muscle of the rectum. Within each cushion is a venous plexus that is fed by arteriovenous communication. Hemorrhoids results from the pathological change in prolapsed anal column [1].

Internal hemorrhoids are classified into four degrees depending on the extent of prolapse. This classification is helpful in assessing different therapies.

Grade I: bleeding without prolapse

Grade II: prolapse with spontaneous reduction

Grade III: prolapse with manual reduction

Grade IV: incarcerated, irreducible prolapse 
Patients present with bright red blood per rectum or a prolapsing anal mass. Soiling may occur in third- or fourth-degree hemorrhoids as a result of impaired continence or mucous discharge that can lead to perianal irritation. Some patients may present with incarcerated or strangulated hemorrhoids. Some patients may present with anemia [1].

Assessment should include anoscopy and digital rectal examination (DRE) in left lateral position. The hemorrhoid cushions can be viewed (by using anoscope) in the left lateral, right anterior, and right posterior positions, that is, $3,7,11$ O'clock in lithotomy position. Sigmodoscopic exclusion of rectal disease is essential in establishing the diagnosis.

Treatment is classified in three categories as per the guidelines issued by the American Society of Colon and Rectal surgeons [2]: (a) conservative treatment, which consists of in increasing dietary fiber, avoiding straining at stools, and prolonged staying on toilet. Sitz baths in ointments containing local anesthetic, mild astringent, and steroids that provide short-term relief, (b) minimally invasive procedures which include RBL [3], injection sclerotherapy [4], infrared coagluation [5], anal stretch [6], cryosurgery [7], laser hemorrhoidectomy [8], and Doppler-guided hemorrhoidal artery ligation [9], and (c) surgical therapy includes closed hemorrhoidectomy [10], open hemorrhoidectomy [11], stapled hemorrhoidectomy [12], and Whitehead hemorrhoidectomy [13].

The present study evaluates the results of RBL, and the hemorrhoidectomy and the comparative evaluation of both the methods.

\section{Material and Methods}

Detailed clinical history was taken in all the patients with particular reference to bleeding per rectum, constipation, prolapse, painful defecation discharge per rectum, dietary habits, and family history of hemorrhoids. Detailed general physical exam was done in all. Each patient was subjected to local examination (DRE), proctoscopy, and sigmoidoscopy.

Baseline investigations including $\mathrm{CBC}$, KFT, B sugar, urine exam, CXR, and ECG were done in all patients. All the patients were given proctoclysis enema in the evening and the morning before surgery or RBL.

All the 50 patients of the hemorrhoidectomy group were kept fasting $8 \mathrm{~h}$ prior to surgery.

All the patients were advised to report in causality in case of any complication in the form of bleeding per rectum, pain, fever, swelling, discharge, etc. Final assessment was done at 6 months postprocedure regarding effect of treatment on rectal bleeding, prolapse, pain, and subjective improvement (patient assessment).
Table 1 Proctoscopic examination of $\mathrm{R}$ group

\begin{tabular}{llll}
\hline S.No & Findings & No. of cases & $\%$ age \\
\hline 1 & Grade I Hemorrhoid & 0 & $0 \%$ \\
2 & Grade II (spontaneous reduction) & 36 & $72 \%$ \\
3 & Grade III (manual reduction) & 14 & $28 \%$ \\
\hline
\end{tabular}

\section{Results}

Of the 100 patients, 70 were males and 30 were females (M: $\mathrm{F}=7: 3$ ). In the rubber band ligation ( $\mathrm{R})$ group, 33 patients were males and 17 females $(\mathrm{M}: \mathrm{F}=1.9: 1)$, and in the hemorrhoidectomy $(\mathrm{H})$ group, 37 were males and 13 females $(\mathrm{M}$ : $\mathrm{F}=2.8: 1$ ). The age of patients ranged from 17 to 70 years in both $\mathrm{R}$ and $\mathrm{H}$ groups with a mean age of 43.5 years. The commonest symptoms were prolapse (100\%) and bleeding P/R (94\%), and the least common was discharge per rectum (23\%).

All the patients were nonvegetarians with less fiber in their diet. Positive family history of hemorrhoids was present in 30 patients (19 in $\mathrm{R}$ group and 11 in $\mathrm{H}$ group).

In the $\mathrm{R}$ group, 12 patients had anemia, 4 had uncontrolled hypertension, 2 had chronic obstructive pulmonary disease (COPD), 1 was case of treated tubercular meningitis with residual disability, and 1 was a cardiac patient (RHD with MS). In the $\mathrm{H}$ group, 5 patients had anemia, 12 had hypertension controlled on drugs, and 1 was case of COPD.

Relative contraindications to surgery/anesthesia were present in 10 patients, which included 3 patients $(6 \%)$ with severe anemia, 1 patient $(2 \%)$ with severe COPD, 4 patients ( $8 \%$ ) with severe uncontrolled HTN, 1 patient ( $2 \%$ ) RHD with severe MS in, and 1 patient ( $2 \%$ ) TBM with residual disability. They were subjected to RBL.

Proctoscopic examination revealed that $62 \%$ patients had grade II hemorrhoids and $38 \%$ had grade III hemorrhoids in all. In the R group, 36 of the patients (72\%) had grade II and $14(28 \%)$ had grade III hemorrhoids. In the H group, 26 patients $(52 \%)$ had grade II and 24 patients (48\%) had grade III hemorrhoids (Tables 1 and 2).

Assessment at 6 months postprocedure revealed the following points:

1. RBL resulted in no bleeding in $70 \%$ of patients compared with $80 \%$ after hemorrhoidectomy.

2. There were 36 patients in the $\mathrm{R}$ group and 26 patients in the $\mathrm{H}$ group with grade II hemorrhoids (spontaneous reduction of prolapse) 28 patients $(77 \%)$ had no

Table 2 Proctoscopic examination in $\mathrm{H}$ group

\begin{tabular}{llll}
\hline 1 & I & 0 & $0 \%$ \\
2 & II & 26 & $52 \%$ \\
3 & III & 24 & $48 \%$ \\
\hline
\end{tabular}


Table 3 Effect on spontaneous reduction of prolapse (grade II hemorrhoid) by RBL

\begin{tabular}{llll}
\hline S.No & Effect & No. of cases & $\%$ age \\
\hline 1 & No prolapsed & 28 & $77 \%$ \\
2 & Improved & 6 & $16 \%$ \\
3 & No change & 2 & $6 \%$ \\
\hline
\end{tabular}

prolapse following RBL compared with 24 (92\%) after hemorrhoidectomy (Tables 3 and 4).

3. Effect on manual reduction of prolapse (grade III hemorrhoids): There were 14 patients (with grade III hemorrhoids in the R group and 24 patients with grade III hemorrhoids in the $\mathrm{H}$ group. Fifty percent of patients showed no prolapse after RBL compared with $87.5 \%$ after hemorrhoidectomy (Tables 5 and 6).

4. Patient assessment of treatment following RBL showed excellent improvement in 32 patients (64\%), moderate improvement in 10 patients $(20 \%)$, and no improvement in 8 patients (16\%) compared with $70 \%, 20 \%$, and $10 \%$, respectively following hemorrhoidectomy.

5. Twenty percent patients required analysis following RBL compared with $100 \%$ following hemorrhoidectomy up to $48 \mathrm{~h}$ of the procedure.

\section{Discussion}

RBL produces mucosal ulcer that heals by cicatrisation fixing mucosa to underlying skin, which prevents decent of hemorrhoids during defection. The technique can be performed on OPD basis in a few minutes without anesthesia. Hemorrhoidectomy aims to excise most of the hemorrhoidal plexus of veins to produce symptomatic relief. However, it has to be performed on inpatient basis requiring anesthesia and further hospital stay in post-op period of 2-5 days.

The mean age of patients in our series was 43.5 years (17-70 years). This is comparable to that reported by Murie et al. [14] who reported the mean age of $50 \pm 12$ years, Konings et al. [15] who reported the mean age of 51 years and Hosch et al. [16] who reported the mean age of 50 years.

The overall male:female ratio in our study was 70:30 (7:3) with 2.8:1 in the $\mathrm{H}$ group and 1.9:1 in the $\mathrm{R}$ group.

Table 4 Spontaneous reduction of prolapse by haemorrhoidectomy

\begin{tabular}{llll}
\hline S.No & Effect & No. of cases & $\%$ age \\
\hline 1 & No prolapsed & 24 & $92 \%$ \\
2 & Improved & 2 & $8 \%$ \\
3 & No change & 0 & $0 \%$ \\
\hline
\end{tabular}

Table 5 Effect of RBL on grade III hemorrhoid (manual reduction of prolapse)

\begin{tabular}{llll}
\hline S.No & Effect & No. of cases & $\%$ age \\
\hline 1 & No prolapsed & 7 & $50 \%$ \\
2 & Improves & 4 & $28 \%$ \\
3 & No change & 3 & $21 \%$ \\
\hline
\end{tabular}

These finding correlate well with male preponderance noted by Stefan et al. [16] (M:F=2.4:1), Sohn et al.[17] (2:75:1), Murie et al. [14] (M:F=1.8:1 in the $H$ group and 1.86:1 in the $\mathrm{R}$ group), Murie et al. [18] (M:F=2:1 in the R group and 1.9:1 in the $\mathrm{H}$ group).

Rectal bleeding in our series was present in $94 \%$ patients ( $92 \%$ in the $\mathrm{R}$ group and $96 \%$ in the $\mathrm{H}$ group), which favorably correlates with the findings of Steinberg et al. [19] (91.2 \%), O’Regan et al. [20] (98\%), Hosch et al. [16] ( $82 \%$ ), and Murie et al. [18] (84\%).

Rectal prolapse was present in $100 \%$ of our patients. This is comparable to the findings of Murie et al. [18] $(100 \%)$. However, our study is at variance with that of Steinberg et al. [19] who reported prolapse in $64 \%$ and O'Regan et al. [20] who reported prolapse in $62 \%$ of their patients.

Discharge per rectum which was present in $23 \%$ of our patients comparable with that of Steinberg et al. [19] $(23.2 \%)$ and varies with the series of Murie et al. [18] (53\%).

In our series of patients, pain was reported in $36 \%$, both in the $\mathrm{H}$ and $\mathrm{R}$ groups. In the series of Murie et al. [18] pain was reported in $44 \%$ of patients (36\% in R group and $52 \%$ in $\mathrm{H}$ group), and in the study by Vellacott and Hardcastle [21] (35\%).

Constipation in our series was reported in $64 \%$ of patients, which was at variance with that of Broader et al. [22] (10\%). This variance could be explained by sociocultural and climatic condition of our valley, as all the patients $(100 \%)$, were nonvegetarians with decreased fiber content in their diets.

Anemia in our series was present in $17 \%$ cases. Six percent cases had severe anemia, which contraindicated surgery. This is at variance with the study conducted by Wolff et al. [23] who reported anemia in $4 \%$ of 484 patients he studied.

Table 6 Effect of haemorrhoidectomy on grade II hemorrhoids

\begin{tabular}{llll}
\hline S.No & Effect & No. of cases & $\%$ age \\
\hline 1 & No prolapsed & 21 & $87.5 \%$ \\
2 & Improve & 3 & $12.5 \%$ \\
3 & No change & 0 & 0 \\
\hline
\end{tabular}


At 6-month follow-up we observed no bleeding in $70 \%$ in the $\mathrm{R}$ group and $80 \%$ in the $\mathrm{H}$ group. Improvement of bleeding was reported by $20 \%$ in the R group and $16 \%$ in the $\mathrm{H}$ group and no improvement by $10 \%$ in the $\mathrm{R}$ group and $4 \%$ in the $\mathrm{H}$ group. Above findings closely correlated with those of Murie et al. [18] and Steinberg et al. [19] and Panda et al. [24].

These findings suggest RBL as an excellent method and equally efficient as hemorrhoidectomy in control of bleeding [19].

In our study, $77 \%$ patients had no prolapse following RBL compared with $92 \%$ following hemorrhoidectomy in grade II hemorrhoids. These findings closely correlate with findings of Murie et al. [25], Steinberg et al. [19], Panda et al. [24]. These findings indicate that RBL produces comparable results to hemorrhoidectomy in prolapse with spontaneous reduction (grade II) Murie et al. [25].

Cheng et al. [26] report that hemorrhoidectomy is good in curing the disease, but higher possibility of post-op pain, complications and longer hospital study would not justify its use in the treatment of second hemorrhoid. Lewis et al. [27] are of view that RBL is cheaper alternative to hemorrhoidectomy and reduces the demand for beds and pressure on surgical waiting list.

For grade 111 hemorrhoids (prolapse requiring manual reduction). We reported no prolapse in $50 \%$ of our patients following RBL compared with $87.5 \%$ following hemorrhoidectomy, improvement in prolapse following $\mathrm{RBL}$ in $28 \%$ compare to $12.5 \%$ after hemorrhoidectomy and no change in $21 \%$ in RBL group compared to $0 \%$ in Hemorrhoidectomy group. These findings are age comparable to those of Murie et al. [14]. These findings suggest that $\mathrm{RBL}$ is not as effective as hemorrhoidectomy in the treatment of large hemorrhoid requiring manual reduction (grade III). Lewis et al. [27] report that cryotherapy and RBL are unsuitable for treatment of large prolapsing hemorrhoids; however, they may be considered as cost-effective and acceptable treatment in short term, but in long term some patients will develop recurrence, requiring hemorrhoidectomy.

In our series, patient assessment of treatment modality showed that $64 \%$ reported RBL as excellent modality compared with $70 \%$ following hemorrhoidectomy, $20 \%$ were moderately satisfied with RBL compared with $20 \%$ following hemorrhoidectomy and $16 \%$ reported no improvement in RBL group compared with $10 \%$ following hemorrhoidectomy. These findings correlate well with those of Murie et al. [14] and Bayer et al. [28]. However, Cheng et al. [26] reported that $96 \%$ patients were cured at 1 year following hemorrhoidectomy compared with $83 \%$ following RBL. Almost similar findings were observed by Steinberg [19] and MacRae and Mcleod [29].
In our study, $100 \%$ patients required postoperative analgesia following hemorrhoidectomy compared with $20 \%$ patients requiring analgesia following RBL, which correlate well with the study of O'Regan et al. [20] and Wienert [30].

RBL is associated with fever complications and less pain than hemorrhoidectomy. Hemorrhoidectomy is often a painful procedure, involving a hospital stay of 5-10 days with additional time off work of 2-6 weeks. Furthermore, it is not without complications such as secondary hemorrhage, stenosis, or incontinence [31].

\section{Summary and Conclusion}

- Hemorrhoidectomy and RBL are equally effective, especially in second-degree hemorrhoids; however, hemorrhoidectomy that aims to excise most of the hemorrhoid plexus of veins produces lasting results. But patients who suffer persistent and severe recurrent symptoms after RBL can be treated by further RBL.

- Hemorrhoidectomy is a painful procedure that involves hospital stay of 5-10 days with an additional time off work of 2-6 weeks and is associated with complications such as secondary hemorrhage, stenosis, or incontinence.

- RBL is safe, pain-free procedure, does not involve anesthesia, and is an outpatient procedure. Patients report back to work soon after the procedure.

- By restoring to the policy of RBL as the first choice in second-degree hemorrhoids, many a hospital beds can be saved for more sick patients and it can take pressure off the surgical waiting lists.

- RBL, although not as effective as hemorrhoidectomy, in third-degree hemorrhoids does improve bleeding and prolapse. Hence, it is highly recommended for patients who are unfit for surgery or have concurrent disease which contraindicates anesthesia.

We support the view that RBL should be considered the first-line treatment in second-degree hemorrhoids. However, in the third-degree hemorrhoids, hemorrhoidectomy achieves better results and RBL is recommended as the first-line of treatment for those patients in whom their is contraindication for surgery or anesthesia.

\section{References}

1. Thomson WH (1975) The nature of hemorrhoids. BJS 62:542-552

2. American society of colon and rectal surgeons (1993) Practice parameters for the treatment of haemorrhoids. Dis Colon Rectum $36: 1118-1120$

3. Barron J (1963) Office ligation treatment of hemorrhoids. Dis Colon Rectum 6:109-113 
4. Sato SG, Novell JR, Khowry G, Winslet MC, Lewis AA (1993) Long term results of large dose, single-session phenol injection sclerotherapy for hemorrhoids. Dis Colon Rectum 36:958-691

5. Leicesters RS, Nicholls RJ, Chair M et al (1981) Infra red coagulation: a new treatment for hemorrhoids. Dis Colon Rectum 24:602-605

6. Lord PH (1969) A day case procedure for the cure of third degree hemorrhoids. Br J Surg 56:747-749

7. Buls JG, Goldberg SM (1978) Modern management of hemorrhoids. Surg Clin North Am 58:469

8. Hodgson WJ, Morgan J (1995) Ambulatory haemorrhoidectomy with $\mathrm{CO}_{2}$ laser. Dis Colon Rectum 38:1265

9. Moringa K, Hasuda K, Ideda T et al (1995) A novel therapy for internal hemorrhoids: ligation of the haemorrhoidal artery with a newly devised instrufment (Moricorn) in conjunction with a Doppler flow meter. Am J Gastroenterol 90:610

10. Ferguson JA, Mazier WP, Ganchrow MI, Friend WG (1971) The closed technique of hemorrhoidectomy. Surgery 70:480

11. Reis Neto JA, Quilici FA, Cordeiro F, Reisjunior JA (1992) Open versus semi open hemorrhoidectomy: a random trial. Int Sug 77:84

12. Rowsell M, Bello M, Hemingway DM (2000) Circumferential mucosectomy (stapled haemorrhoidectomy) versus conventional haemorrhoidectomy: randomised controlled trial. Lancet $355: 779$

13. Whitehead W (1882) The surgical treatment of hemorrhoids. Br Med J 1:148

14. Murie JA, Mackenzie I, Sim AJ (1980) Comparison of rubber band ligation and hemorrhoidectomy for second and third degree haemorrhoids: a prospective clinical trial. BJS 67(11):786-788

15. Konings M, Debets JM, Baeten CG (1999) Rubber band ligation of hemorrhoids: symptoms almost gone after 6 weeks but many patients need retreatment in the long run. Ned Tijdschr Geneeskd 143(24):1265-8

16. Hosch SB, Knoefel WT, et al (1998) Surgical treatment of piles, prospective randomized study of Parks vs Milligan Morgan hemorrhoidectomy. Dis Colon Rectum Feb 159-164

17. Sohn N, Aronoff JS, Cohen FS et al (2001) Transanal haemorrhoidal dearterialization is an alternative to operative haemorroidectomy. Am J Surg 182(2001):515-519

18. Murie JA, Sim AJ, Mackenzie I (1981) The importance of pain, pruritis and soiling as symptoms of haemorrhoids and their response to haemorrhoidectomy or rubber band ligation. BJS 68 (4):247-249

19. Steinberg DA, Liegois HJ, Willaims A (1975) Long term review of the results of rubber band ligation of haemorrhoids. BJS 62:144146

20. O'Regan PJ (1999) Disposable device and a minimally invasive technique for rubber band ligation of haemorrhoids. Dis Colon Rectum 42(5):683-685

21. Vellacott KD, Hardcastle JD (1980) Is continued anal dilatation necessary after a Lord's procedure for haemorrhoids. BJS 67:658659

22. Broader JH, Gunn IF, Williams A (1974) Evaluation of a bulk forming evacuant in the management of haemorrhoids. BJS 61:142-144

23. Wolff BJ, Culpp CE (1988) The whitehead haemorrhoidectomy. An unjustly maligned procedure. Dis Colon Rectum 31:587-590

24. Panda AP, Laughton JM, Elder JB, Gillespie IE (1975) Treatment of haemorrhoids by rubber band ligation. Digestion 12 (2):85-91

25. Murie JA, Sim AJ, Mackenzie I (1982) Rubber band ligation versus haemorrhoidectomy for prolapsing haemorrhoids: a long term prospective clinical trial. BJS 69:536-538

26. Cheng FC, Shum DW, Ong GB (1981) The treatment of second degree haemorrhoids by injection, rubber band ligation, maximal anal dilatation and haemorrhoidectomy: a prospective clinical trial. Aust NZ J Surg 51(5):458-462

27. Lewis AAM, Rogers HS, Leighton M (1982) Trial of maximal anal dilatation, cryotherapy and elastic band ligation as alternative to haemorrhoidectomy in the treatment of large prolapsing haemorrhoids. BJS 70:54-56

28. Bayer I, Myslovaty B, Picovsky BM (1996) Rubber band ligation of hemorrhoids: convenient and economic treatment. J Clin Gastroenterol 23:50-52

29. MacRae HM, Mcleod RS (1995) Comparison of haemorrhoidal treatment modalities: a meta-analysis. Dis Colon Rectum 38:687-694

30. Wienert V (1977) Ambulatory hemorrhoidectomy through rubber band ligation-review of the literature. Fortschr Med 95 (25):1619-1622

31. Bennett RC, Friedman MHW, Goligher JC (1963) Late results of haemorrhoidectomy by ligation and excision. BMJ 2:216-219 